\title{
O Juazeiro e a Geração de Conceitos Químicos
}

Romário J onas de Oliveira* (Graduando em Licenciatura em Química na Universidade Federal de Campina Grande - UFCG);

J osé Carlos Oliveira Santos (Professor na UABQ/CES na Universidade Federal de Campina Grande UFCG)

*E-mail: romario.jonas@live.com

Resumo: Abrangendo desde o nordeste até o norte de Minas Gerais, na região da caatinga, o popularmente conhecido "Juá" ou Juazeiro (Ziziphus Joazeiro Mart.) é uma planta que tem grande potencial medicinal, científico e econômico, que podem ser utilizadas de forma a contextualizar o ensino de química que cada vez mais vem se tornando fragmentado e cheio de lacunas. O objetivo desse estudo é sugerir possíveis conceitos e conteúdos da disciplina de química que podem ser trabalhados através da análise das propriedades e dos benefícios do Ziziphus Joazeiro. Para isso foi feita uma revisão bibliográfica sobre as propriedades da planta bem como de seus usos que podem ser diversos. São muitos os conceitos químicos que podem ser trabalhados através do juazeiro. Nesse trabalho apresentamos alguns deles tais como polaridade das moléculas, substâncias hidrofílicas e hidrofóbicas, substâncias antioxidantes, solubilidade, entre outros que podem ser estudados. É de grande importância o estudo de plantas de uma região tão ameaçada como a caatinga. Esse estudo serviu de partida para que professores passem a modificar sua maneira de ensinar e buscar caminhos que permitam que o aprendizado do aluno se dê de forma positiva e satisfatória.

Palavras-chave: Ensino e aprendizagem; Ensino de química; Ziziphus Joazeiro, experimentação; contextualização.

Espaço reservado para organização do congresso. 


\section{Introdução}

As maiores dificuldades para que os alunos aprendam química são demonstradas em vários níveis de ensino, pois, os estudantes não percebem a validez e o significado do que estudam. Isso se deve muitas vezes a contextualização não adequada dos conteúdos com a realidade que vive o aluno, não despertando assim o interesse e a motivação do mesmo pela disciplina.

Muitas vezes os professores ficam presos apenas às informações contidas no livro didático e conduzem a aula de uma forma tradicional sem nenhum tipo de contextualização. Isso se deve ao fato de que os docentes não têm tempo, uma vez que a pouca remuneração fazem os mesmos terem que trabalhar em mais de uma escola, ficando assim, com uma carga horária muito elevada onde não da para encaixar um horário para melhor planejar a sua metodologia de ensino. Outro grande problema é a falta de compromisso tanto dos estudantes que não querem parar para estudar como também de alguns professores que param no tempo e não buscam melhorar a sua prática docente, mesmo tendo horários suficientes e materiais a disposição para executar tal tarefa.

Dessa forma o entendimento do aluno sobre o ensino de química vai ficando complicado, pois, o mesmo está sendo feito de forma fragmentada deixando diversas lacunas e espera-se que um dia o estudante junte todos esses fragmentos e preencha todas essas lacunas garantindo assim um aprendizado como se fosse uma tarefa simples e rápida. Sabemos que seguindo esse caminho o aluno nunca irá compreender os conceitos da ciência química e como também saber relacioná-los com o seu cotidiano e o dia a dia.

Uma forma de solução para facilitar a compreensão dos alunos acerca dos conceitos químicos é a sua relação com fatos e coisas de seu meio, ou seja, coisas que ele conhece como a água, alimentos, plantas entre outros. Uma planta muito importante e que tem essa capacidade de ser estudada proveitosamente pela química é o Juazeiro (Ziziphus Joazeiro Mart.) espécie de grande potencial da caatinga, que ocorre desde o nordeste até o norte de Minas Gerais, apresenta grande importância econômica, ecológica e medicinal, desde a produção de lenha e carvão até no tratamento de doenças. Também é utilizado na fabricação de cosméticos e na higiene bucal devido à presença de saponinas em sua composição química.

Seguindo a linha de pensamento em buscar novas formas de contextualizar o conhecimento químico e como também valorizar espécies típicas de regiões de clima seco que não são tão aproveitadas o objetivo desse estudo é sugerir possíveis conceitos e conteúdos da disciplina de química que podem ser trabalhados através da análise das propriedades e dos benefícios do Ziziphus Joazeiro, o popular juá. Incentivando, dessa maneira, a professores que se sintam interessados em mudar para melhor ou então acrescentar novas formas de metodologias de ensino do conteúdo químico em sala de aula tornando a aula mais atrativa e diversificada.

\section{Material e Métodos}

O presente trabalho foi desenvolvido na Escola Estadual de Ensino Médio Professor Lordão, localizada na zona urbana do município de Picuí no estado da Paraíba, tendo um período de execução ocorrido entre maio e julho do corrente ano. O público alvo da pesquisa foram alunos de turmas do terceiro ano do Ensino Médio regular.

O objetivo desse estudo foi sugerir possíveis conceitos e conteúdos da disciplina de química que podem ser trabalhados através da análise das propriedades e dos benefícios do Ziziphus Joazeiro o popular juá. Para isso foi feita uma revisão bibliográfica sobre as propriedades da planta bem como de seus usos que podem ser diversos. São muitos os conceitos químicos que podem ser trabalhados através do juazeiro, nesse trabalho apresentamos alguns deles tais como polaridade das moléculas, substâncias hidrofílicas e hidrofóbicas, substâncias antioxidantes, solubilidade, entre outros que podem ser estudados. 


\section{Resultados e Discussão}

\subsection{Um pouco sobre o Ziziphus J oazeiro}

O Juazeiro (Ziziphus Joazeiro Mart.) popularmente chamado de "juá” é uma das espécies promissoras da caatinga (Bioma ameaçado no Brasil) e tem seu uso em xampus e entre outros produtos devido à presença de saponinas em várias partes da planta (OLIVEIRA, 2012). Saponina vem do latim "sapo", que significa sabão, pois, forma espuma quando extratos ricos nessa substância são agitados em água (RIBEIRO, 2013).

O juá ocorre desde o nordeste até o norte de Minas Gerais. Apresenta grande importância econômica e ecológica, onde é utilizado localmente para produção de lenha e carvão, arborização de ruas e jardins, além de possuir frutos comestíveis. É utilizado também na medicina popular como expectorante no tratamento de bronquites e de úlceras gástricas, na fabricação de cosméticos além de servir na alimentação de animais principalmente no período de secas (LORENZI, 2009).

Segundo Silva (2010), a planta possui uso como antisséptico bucal, contra problemas dermatológicos, como cicatrizante e as raspas do caule reduzidas a pó, podem ser usados como dentifrício. Ainda analisando o trabalho de Silva foi possível perceber que o Juazeiro possui substâncias com atividade antioxidante, ou seja, substâncias que retardam ou previnem significativamente a oxidação de lipídios ou outras moléculas ao inibirem a iniciação e/ou propagação da reação de oxidação em cadeia e ainda captura de radicais livres, que não podem estar em altas quantidades no organismo, pois, sua presença tem sido correlacionada com um grande número de doenças, não possuindo papel etiológico na grande maioria dos estados patológicos, mas que participam diretamente dos mecanismos fisiopatológicos que determinam a continuidade e as complicações presentes nesses processos.

As imagens 1 e 2 abaixo mostram as raspas da casca da planta e o seu fruto ainda não colhido respectivamente.

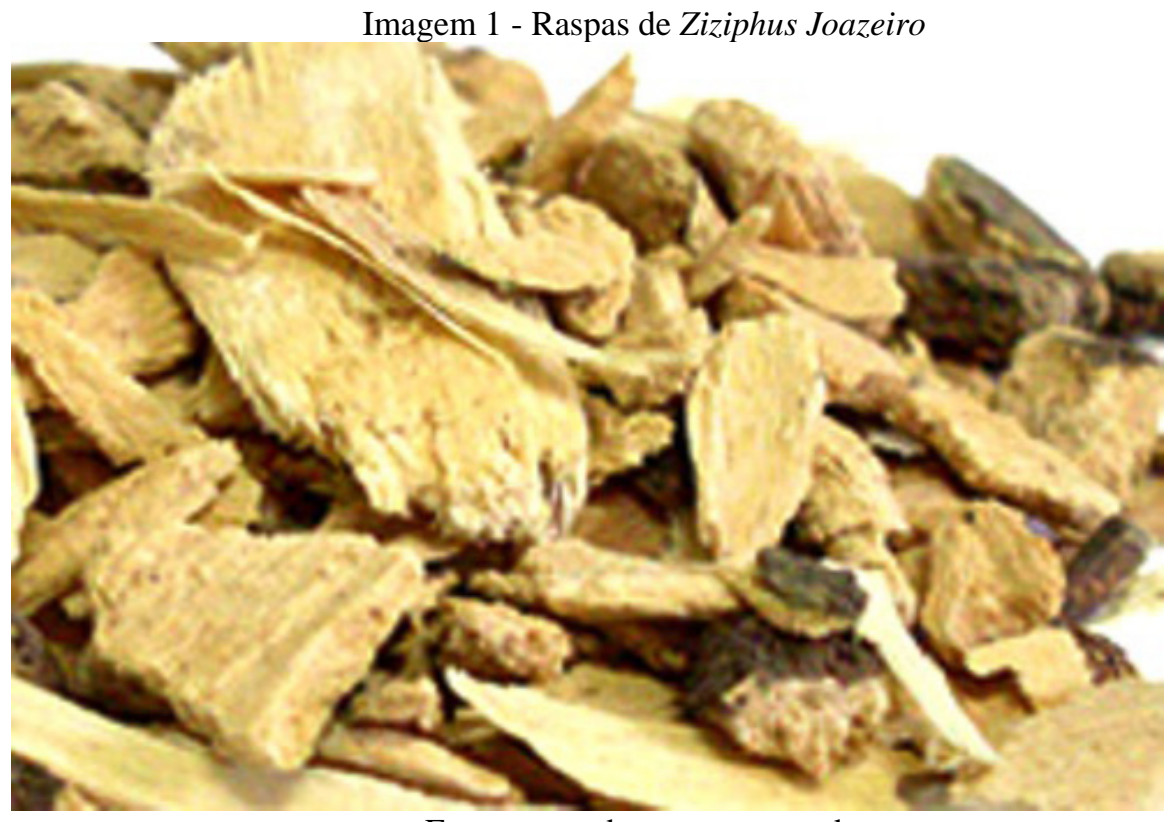

Fonte: www.baraoervas.com.br 


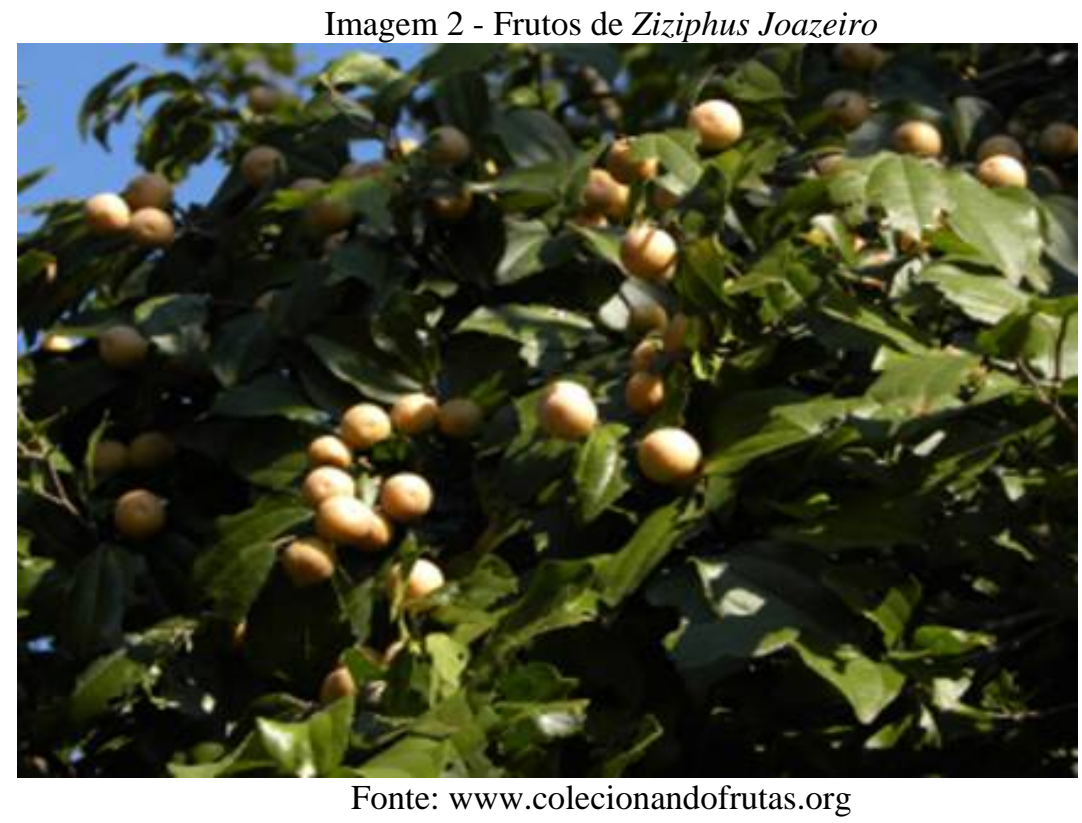

\subsection{Conteúdos químicos a serem abordados através do Ziziphus J oazeiro}

São diversas as possibilidades de se aproveitar o Ziziphus Joazeiro quimicamente. Como mencionado anteriormente essa planta apresenta saponinas em sua composição química. A saponina é uma substância que apresenta parte de sua molécula hidrofóbica e parte hidrofílicas, ou seja, são partes que respectivamente não tem afinidade com a água e partes que possuem essa afinidade.

Apenas com a análise dessa informação o professor pode trabalhar com alguns conceitos químicos, tais como polaridade de moléculas, pois a saponina apresenta uma parte polar e outra apolar, solubilidade de substâncias em água e afinidades de substâncias com gorduras e com água.

Outra possibilidade de estudo é a composição química da planta, uma vez que ela não apresenta apenas a saponina, mas sim diversas outras sustâncias bem como também, a composição do solo onde está situada a planta.

O juazeiro possui substâncias com atividade antioxidante, sabendo disso o professor pode usar dessa informação no estudo da química orgânica e relacionar com os conteúdos de reações orgânicas abordando a captura de radicais livres processo muito importante em nosso organismo que tem capacidade de prevenir algumas doenças bem como envelhecimento precoce.

\section{Considerações Finais}

O ensinar química exige compromisso e a busca de novas metodologias é uma das funções dos professores dessa ciência. Não podemos deixar que os estudantes aprendam de forma forçada e decorada, é preciso que haja contextualização e estudos como esse trabalho mostra que é possível no mínimo conseguir relacionar conteúdo com coisas cotidianas de cada aluno.

Cabe a criatividade e ao esforço de cada docente procurar melhorar sua prática. A análise das propriedades de uma planta como o Ziziphus Joazeiro e sua relação com alguns conceitos químicos é uma partida para a mudança na forma de ensinar e garantir resultados satisfatórios dos alunos ouvintes em sala. 


\section{The Juazeiro and Chemical Concepts Generation}

Albstract: Ranging from the northeast to the north of Minas Gerais, in the region of the caatinga, the popularly known "J ua" or J uazeiro (Ziziphus Joazeiro Mart.) Is a plant that has great medical, scientific and economic potential, which can be used to provide context chemical education which increasingly is becoming fragmented and full of gaps. The aim of this study is to suggest possible concepts and chemistry discipline of content that can be worked by analyzing the properties and benefits of Zziphus Joazeiro. For it was made a bibliographic review of the plant's properties and their uses can be different. There are many chemical concepts that can be worked through juazeiro. In this paper we present some of them such as polarity of the molecules, hydrophilic and hydrophobic substances, antioxidants, solubility, and others that can be studied. It is of great importance the study of plants of a region so threatened as the caatinga. This study was the starting so that teachers start to change their way of teaching and find ways to enable student learning takes place in a positive and satisfactory.

Keywords: Teaching and learning; Chemistry education; Ziziphus Joazeiro, experimentation; contextualization.

\section{Referências bibliográficas}

LORENZI, H. Árvores Brasileiras: Manual de I dentificação e Cultivo de Plantas Arbóreas Nativas do Brasil. V. 3. Instituto Plantarium de Estudos da Flora LTDA, São Paulo: 2009.

OLIVEIRA, A. K.; COELHO, M. F. B.; MAIA, S. S. S.; DIÓGENES, F. É. P.; FILHO, S. M. Atividade Alelopática de Extratos de Diferentes Partes de Juazeiro (Ziziphus Joazeiro Mart. - Rhamnaceae). Acta Brasílica, v. 26, n 3, 2012.

RIBEIRO, B. D.; ALVIANO, D. S.; BARRETO, D. W.; COELHO, M. A. Functional Properties of Saponins from Sisal (Agave sisalana) and juá (Ziziphus Joazeiro): Critical Micellar Concentration, Antioxidant Andantimicrobial Activities. Colloids and Surfaces A: Physicochemical and Engineering Aspects, v. 43, nº 6, 2013.

SILVA, T. C. L.; ALMEIDA, C. C. B. R.; VERAS FILHO, J.; PEIXOTO SOBRINHO, T. J. S.; AMORIM, E. L. C.; COSTA, E. P.; ARAÚJ O, J. A. Atividades Antioxidante e Antimicrobiana de Ziziphus Joazeiro Mart. (Rhamnaceae): Avaliação Comparativa Entre Cascas e Folhas. Revista de Ciências Farmacêuticas Básica e Aplicada. v. 32, n 2, 2010. 